\title{
Single Dose Epidural Block for Infra Umbilical Surface Surgery in Children, a Surgeon's Perspective
}

\author{
Vivek Gharpure ${ }^{1 *}$ and Sikandar Khan ${ }^{2}$ \\ ${ }^{1}$ Department of Pediatric Surgeon, Children's Surgical Hospital, India \\ ${ }_{2}^{2} J u n i o r$ Resident, Department of General Surgery, Pravara Rural Medical College and Hospital, India
}

*Corresponding author: Vivek Gharpure, Pediatric surgeon, Children’s surgical hospital, 13, Pushpanagari, Aurangabad 431001, India

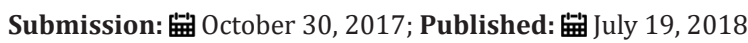

\section{Introduction}

Choice of anesthetic is a difficult decision considering the many options available these days. Each technique has its unique set of difficulties and complications. Anesthesia technique has to be chosen depending upon type of surgery, condition of patient, duration of surgery, safety, and finally cost. It should be possible to select a technique which provides optimum effect at the least possible cost, without compromising safety at any point.

\section{Material and Methods}

Single dose epidural anesthesia, using 0.25\% Bupivacaine, administered via the caudal foramina was administered to 215 patients from Jan 2012 to Dec 2014 in a specialty pediatric surgical centre. The group included 181 boys and 34 girls (Table 1).

\section{Table 1:}

\begin{tabular}{|c|c|c|}
\hline Sr. No & Indication & N \\
\hline 1 & Circumcision & 53 \\
\hline 2 & Inguinal hernia unilateral & 46 \\
\hline 3 & Inguinal hernia bilateral & 7 \\
\hline 4 & Undescended testis & 35 \\
\hline 5 & Chordee correction & 23 \\
\hline 6 & MAGPI & 24 \\
\hline 7 & Bladder stone & 5 \\
\hline 8 & Vesicostomy & 3 \\
\hline 9 & Cutback, anoplasty & 15 \\
\hline 10 & Tendoachilles release & 4 \\
\hline
\end{tabular}

Age ranged from 2 months to 12 years. Weight ranged from $2 \mathrm{~kg}$ to $52 \mathrm{~kg}$. All blocks were administered by a single anesthesiologist. Indications for surgery included,

After iv midazolam, $(0.05$ to $0.1 \mathrm{mg} / \mathrm{kg}$ ) for sedation, Bupivacaine, $0.25 \%$ in the dose range, $0.75 \mathrm{ml}, 1 \mathrm{ml}$ and $1.25 \mathrm{ml} / \mathrm{kg}$ was in jected under all aseptic precautions through the sacral hiatus, after confirming that needle was not in vein. Maximum dose used in any patient was $20 \mathrm{ml}$. Time was noted [1].
Orpharyngeal airway was inserted if patient tolerated it. Patient received appropriate iv fluids, oxygen by facial mask. ECG, oxygen saturation, blood pressure, temperature were monitored. If patient moved or cried, another dose of midazolam was administered. At the conclusion of surgery, vitals were checked, consciousness was confirmed, a analgesic dose of inj paracetamol was administered and patient was returned to recovery room. Time was noted. Standard postoperative care was provided. Patient was examined after 24 hours for specific local complications if any.

\section{Observations}

Block was effective in $213 / 215$ patients, and planned procedures could be completed successfully. $31 / 213$ patients required one additional dose of midazolam. Though some authors have used caudal epidural anesthesia as adjunct to general anesthesia [2], we preferred to utilize caudal block as the sole anesthetic. No patient developed hypoxia, hypotension during surgery or in post-operative period. No patient developed a local complication at 24 hours or 7 days after surgery. Mean induction time, time from patient's entry to OT to commencement of painting was $6 \mathrm{~min} 12$ seconds, (range $3 \mathrm{~min} 47 \mathrm{sec}$ to $8 \mathrm{~min} 15 \mathrm{sec}$ ). Time to shift patient, from application of dressing to moving out was $4 \mathrm{~min} 22 \mathrm{sec}$, (range $2 \mathrm{~min}$ $10 \mathrm{sec}$ to $7 \mathrm{~min} 35 \mathrm{sec}$ ).

\section{Discussion}

A surgeon is worried about non-productive OT time, i.e. time spent in induction of anesthesia, time required for complete emergence, and shifting. For minor procedures like circumcision and inguinal hernia, oftentimes anesthesia induction and reversal take longer than the surgical procedure. Considering OT time limitations in many public hospitals, a faster throughput helps increase surgical efficiency [3].

We observed that epidural block was effective in $99 \%$ patients and provided adequate level and duration of anesthesia to complete infraumbilical, superficial procedures without compromising airway or vital parameters $[4,5]$. 
Block was safely administered to neonates as well as older patients. It will be clear from the table of indications, that most indications occur only in males, thus explaining the preponderance of males in the sample.

Caudal epidural block is particulary safe and effective in former premies presenting with inguinal hernia, as they have a high risk of postoperative apnea after general anesthetic [6,7]. Some authors have used ropivacaine instead of bupivacaine for caudal block, but we preferred bupivacaine.

A full general anesthetic requires the following materials. Oxygen, inhalational agent, ketamine or propofol, short acting muscle relaxant, long acting muscle relaxant, reversing agent, disposable endotracheal tube, anesthesia circuit. It also requires equipment like a laryngoscope and accessories.

Caudal epidural block obviates using these drugs and materials. Airway is not invaded, thus reducing risk of infection, sore throat. We also observed that single dose caudal epidural block reduced induction time from 23 minutes to 6 minutes, and shifting time from 19 minutes to 4 minutes. If there are two or three such procedures planned for the day, this amounts to a considerable saving of OT time and resources. We could not quantify actual savings but they must be significant. In public hospitals, where thousands of procedures are done every year, savings will be substantial.

\section{Conclusion}

Single dose caudal epidural anesthesia can be safely used for short, superficial, infraumbilical surgical procedures. This technique is safe, effective and economical.

\section{References}

1. Schrock, CR, Jones MB (2003) The dose of caudal epidural analgesia and duration of postoperative analgesia. Pediatr Anaesth 13(5): 403-408.

2. Beyaz SG, Tokgöz O, Tüfek (2011) A Caudal epidural block in children and infants: retrospective analysis of 2088 cases. Annals of Saudi Medicine 31(5): 494-497.

3. Alice Edler, Vinit G. Wellis, Caudal Epidural Anesthesia for Pediatric Patients: a safe, reliable and effective method in developing countries, Update in Anaesthesia USA.

4. Ponde VC (2012) Recent developments in paediatric neuraxial blocks. Indian J Anaesth 56(5): 470-478

5. Bouchut JC, Dubois R, Foussat C, Moussa M, Diot N, et al. (2001) Evaluation of caudal anaesthesia performed in conscious ex-premature infants for inguinal herniotomies. Pediatric Anesthesia 11(1): 55-58.

6. Davandra Patel (2006) Epidural analgesia for children. Continuing Education in Anaesthesia Critical Care \& Pain 6(2): 63-66.

7. Manjushree Ray, Mondal SK, Biswas (2003) Caudal analgesia in paediatric patients: Comparison between Bupivacaine and Ropivacaine. Indian J Anaesth 47(4): 275-278.

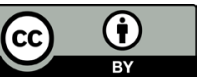

Creative Commons Attribution 4.0 International License

For possible submissions Click Here

\section{Submit Article}

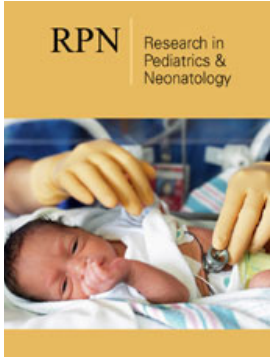

\section{Research in Pediatrics \& Neonatology}

\section{Benefits of Publishing with us}

- High-level peer review and editorial services

- Freely accessible online immediately upon publication

- Authors retain the copyright to their work

- Licensing it under a Creative Commons license

- Visibility through different online platforms 